\title{
A 47 year old man with nonproductive cough and right-sided chest pain
}

\author{
I. Claes*, H. Slabbynck*, L. Bedert*, D. Galdermans*, I. Dierckx**, D. Coolen*
}

\section{Case history}

A 47 yr old man was admitted to our hospital because of persisting nonproductive cough, dyspnoea on exertion and right-sided chest pain of several weeks duration. He was febrile $\left(37.5^{\circ} \mathrm{C}\right)$ and had noticed a weight loss of $5 \mathrm{~kg}$ within the last 2 months. The only pertinent medical history was a cluster headache, for which he was treated intermittently with methysergide. He had taken a cumulative dose of approximately $630 \mathrm{mg}$ over a 21 month period. He was working as a clerk, had no history of asbestos exposure, and smoked one packet of cigarettes per week. Clinical examination was normal, except for a dullness on percussion, diminished breath sounds, and pleural friction at the right base of the thorax.

Laboratory studies showed an erythrocyte sedimentation rate (ESR) of $120 \mathrm{~mm} \cdot \mathrm{h}^{-1}$, a normochromic normo-

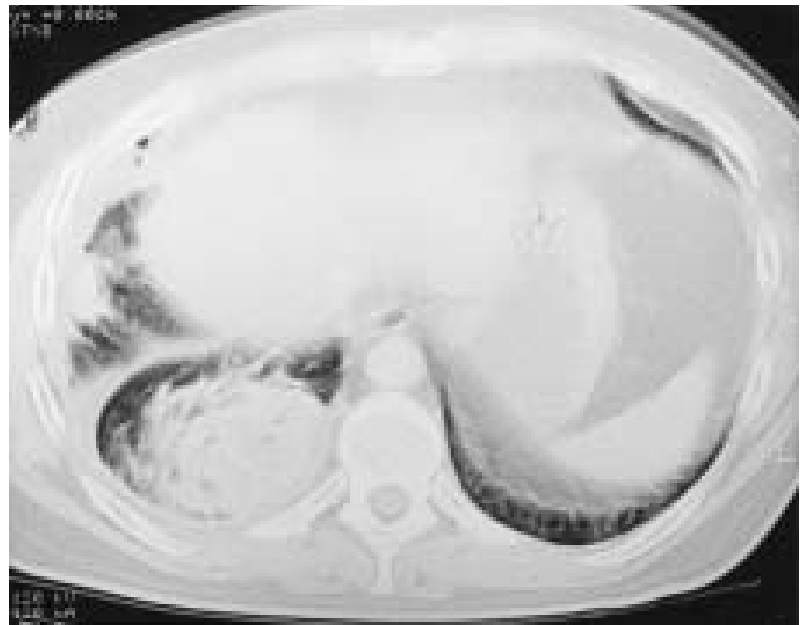

Fig. 1. - Computed tomographic (CT) scan of the thorax on admission at level D10.

Depts of *Pneumology and **Radiology, AZ-Middelheim, Antwerp, Belgium.

Correspondence: I. Claes, Respiratory Division, Academic Hospital, University of Brussels (AZ-VUB), Laarbeeklaan 101, 1090 Brussels, Belgium cytic anaemia with haemoglobin of $103 \mathrm{~g} \cdot \mathrm{L}^{-1}$. Arterial oxygen tension $\left(\mathrm{Pa}_{\mathrm{a}} \mathrm{O}_{2}\right)$ and arterial carbon dioxide tension $\left(P \mathrm{a}, \mathrm{CO}_{2}\right)$ were normal. A chest radiograph revealed a moderate pleural effusion in the right base, with a mass-like lesion in the dorsobasal part of the lung. Adenopathies were absent. Pleural fluid analysis showed a white blood cell count (WBC) of $5,200 \times 10^{6}$ cells $\cdot \mathrm{L}^{-1}$, with $99 \%$ lymphocytes, glucose $0.46 \mathrm{~g} \cdot \mathrm{L}^{-1}, \mathrm{pH}$ of 7.37 , total protein $40 \mathrm{~g} \cdot \mathrm{L}^{-1}$, and lactate dehydrogenase $(\mathrm{LDH})$ $1,520 \mathrm{U} \cdot \mathrm{L}^{-1}$. Search for malignant cells was negative, as were stains and cultures for bacteria, mycobacteria and fungi.

Bronchoscopy was normal, except for an erythematous mucosa in the right lower lobe. Transbronchial biopsies and subsequent open lung biopsy disclosed nonspecific parenchymal fibrosis. Computed tomography (CT) of the thorax was taken on admission (fig. 1) and after 5 months (fig. 2). Pleuroscopy revealed a marked diffuse, white thickening both of the parietal and visceral pleura, with multiple fibrinous adhesions. Biopsies yielded only nonspecific fibrosis. There were no signs of malignancy, granulomas or vasculitis. Stains and cultures for bacteria, mycobacteria and fungi remained negative.

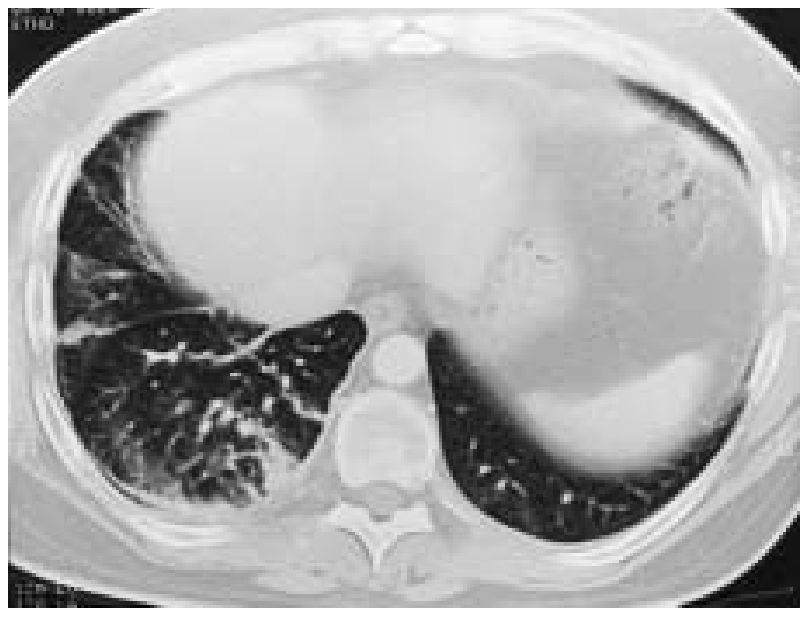

Fig. 2. - Computed tomographic (CT) scan of the thorax 5 months after a therapeutic procedure.

\section{BEFORE TURNING THE PAGE, INTERPRET THE FIGURES, AND SUGGEST DIAGNOSIS AND TREATMENT.}




\section{Interpretation of computerized tomography of the chest}

The CT scan on admission (fig. 1, and explanatory diagram fig. 3) reveals a rounded mass, measuring $78 \times$ $60 \mathrm{~mm}$ in diameter, in contact with the pleura, located in the posterobasal segment of the right lower lobe. The margin oriented towards the hilum is blurred by vessels and bronchi, curving into the mass. There is an associated pleural effusion and thickening, located at the bottom, the lateral chest wall and intrascissural.

\section{Tentative diagnosis: "Pleural effusion and rounded atelectasis secondary to methysergide"}

\section{Treatment and clinical course}

Methysergide was discontinued, after which symptoms progressively abated. A CT scan of the thorax 5 months after cessation of methysergide (fig. 2, and explanatory diagram fig. 4) showed a significant resolution of the rounded atelectasis and complete disappearance of the pleural fluid, with some residual intrascissural pleural thickening.

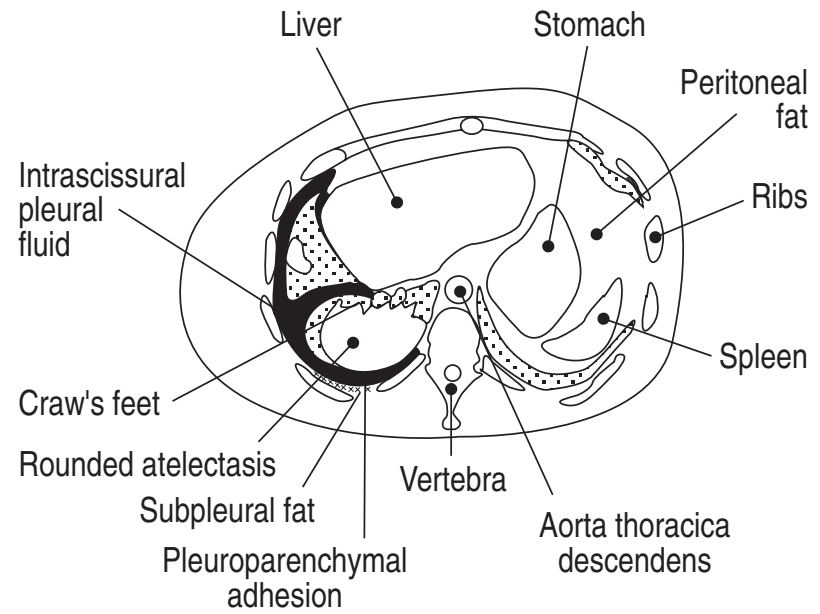

Fig. 3. - Explanatory diagram of figure $1 . \because \because$ : normal aerated lung parenchyma.

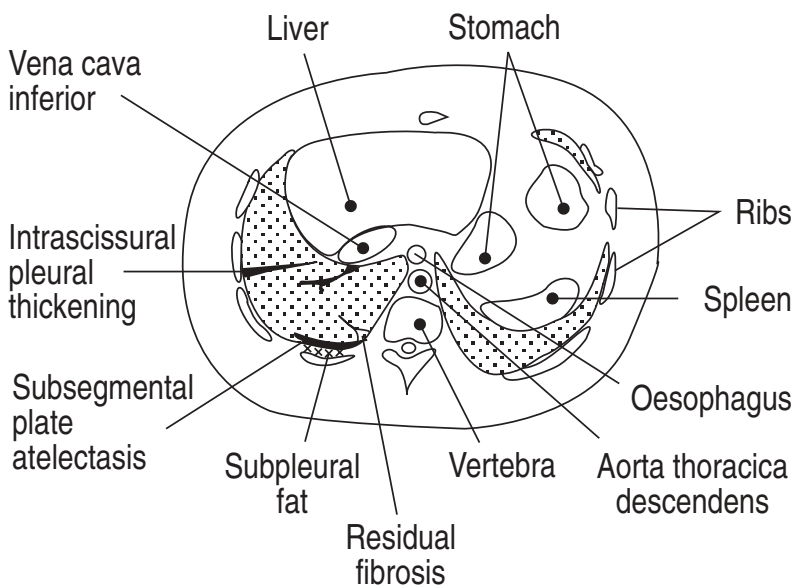

Fig. 4. - Explanatory diagram of figure 2. $\because \because$ : normal aerated lung parenchyma.

\section{Discussion}

Methysergide, an ergot alkaloid, is a serotonin antagonist used for the relief of migraine or cluster headache. Its use is limited because of the high incidence of gastrointestinal intolerance and dermatitis [1]. The more severe complication of retroperitoneal fibrosis has been described in $1 \%$ of patients, and vascular disease (coronary disease, Leriche's syndrome), due to fibrosis and intimal proliferation of the small vessels, has been reported incidentally $[2,3]$.

Pleuropulmonary fibrosis was mainly reported in several small series in the late 1960s [1-7]. Its diagnosis is based on a clinical history and the significant regression of the pleuropulmonary lesions after cessation of the drug, with biopsies of the lesions revealing only nonspecific fibrosis. The potential pleuropulmonary toxicity of methysergide was first described by GRAHAM et al. [4] in three patients in whom symptoms and radiographic signs abated after cessation, and reoccurred after rechallenge with the drug. Its pathogenesis is still unknown $[2,4,5]$. Pleuropulmonary complications have been reported after one month to several years of methysergide therapy, at doses ranging from $1-8 \mathrm{mg}$ daily [1-8]. The present patient took a cumulative dose of approximately $630 \mathrm{mg}$, intermittently over a 21 month period, before respiratory symptoms developed. Symptoms are nonspecific, including dyspnoea, cough, thoracic pain and fever. On clinical examination, dullness on percussion and pleural friction rubs may be found. Pulmonary function tests can be normal, although restrictive impairment has been described $[1,2,6]$.

Chest radiography usually reveals a moderate pleural effusion or pleural thickening, although a "tumour-like mass" in the posterobasal region of the lungs has occasionally been reported $[2,5]$.

CT findings due to methysergide have not been reported previously. In the present patient, CT revealed a rounded mass, with pleural contact in the lung periphery, with the central margin blurred by vessels, and bronchi curving into this mass. Such features on CT are highly characteristic of a rounded atelectasis, and are almost always related to some pathological pleural change, caused mainly by asbestos exposure [9-11]. The absence of a history of asbestos exposure and the lymphocytic pleural exudate led to further investigation of the pleura, mainly to exclude malignancy and infectious disease.

The findings of nonspecific fibrosis of the parietal and visceral pleura during thoracoscopy, together with the reversibility of symptoms and radiological features after cessation of methysergide, led to the final diagnosis of methysergide-induced pleural effusion with rounded atelectasis.

This case illustrates the potential pleuropulmonary toxicity of methysergide and documents several characteristics that have not been described previously, such as the lymphocytic nature of the pleural fluid, thoracoscopic findings of excessive fibrosis of the visceral and parietal pleura, and, at least in the present case, the rounded atelectatic character of the associated mass-like lesion with a tendency to disappear after cessation of the drug.

Keywords: Methysergide, rounded atelectasis. 


\section{References}

1. Gefter WB, Epstein DM, Bonavita JA, Miller WT. Pleural thickening caused by Sansert and Ergotrate in the treatment of migraine. Am J Roentgenol 1980; 135: 375377.

2. Graham JR. Cardiac and pulmonary fibrosis during methysergide therapy for headache. Am J Med Sci 1967; 254: 1-12.

3. Hindle W, Posner E, Sweetnam MT, Tan RSH. Pleural effusion and fibrosis during treatment with methysergide. Br Med J 1970; 1: 605-606.

4. Graham JR, Suby HI, Lecompte PR, Sadowsky NL. Fibrotic disorders associated with methysergide therapy for headache. N Engl J Med 1966; 274: 359-368.

5. Dunn JM, Sloan H. Pleural effusion and fibrosis secon- dary to Sansert administration. Ann Thorac Surg 1973; 15: 295-298.

6. Bays RP. Pleuropulmonary fibrosis following therapy with methysergide maleate: two case reports. J Louisiana State Med Soc 1968; 120: 426-427.

7. Kok-Jensen A, Lindeneg O. Pleurisy and fibrosis of the pleura during methysergide treatment of hemicrania. Scand J Respir Dis 1970; 51: 218-222.

8. Akoun G, Herson S, Huchon G, Marsac J. Les fibroses pleuropulmonaires du méthysergide. Semin Hôp Paris Thérap 1976; 52: 9-13.

9. Hanke R, Kretzschmar R. Rounded atelectasis. Semin Roentgenol 1980; 15: 174-182.

10. Hillerdal G. Rounded atelectasis: clinical experience with 74 patients. Chest 1989; 95: 836-841.

11. McHugh K, Blaquiere RM. CT features of rounded atelectasis. Am J Roentgenol 1989; 153: 257-260. 